\title{
Plasmodium Species: Flow Cytometry and Microfluorometry Assessments of DNA Content and Synthesis
}

\author{
C. J. Janse, ${ }^{*}$ P. H. van Vianen, $\ddagger$ H. J. Tanke, $\ddagger$ B. Mons,$\dagger$ T. Ponnudurai, $§$ and \\ J. P. OVERDULVE*
}

\begin{abstract}
*Department of Tropical Veterinary Medicine and Protozoology, University of Utrecht, P.O. Box 80172, 3508 TD Utrecht, The Netherlands; $¥$ Department of Histochemistry and Cytochemistry, University of Leiden, Wassenaarseweg 72, 2333 AL Leiden, The Netherlands; †Laboratory of Parasitology, Medical Faculty, University of Leiden, Wassenaarseweg 62, 2333 AL Leiden, The Netherlands; and \$Department of Medical Parasitology, Geert Grooteplein Zuid 24, University of Nijmegen, 6500 HB Nijmegen, The Netherlands
\end{abstract}

(Accepted for publication 17 December 1986)

\begin{abstract}
Janse, C. J., Van Vianen, P. H., Tanke, H. J., Mons, B., Ponnudurai, T., and OVfrdulve, J. P. 1987. Plasmodium species: Flow cytometry and microfluorometry assessments of DNA content and synthesis. Experimental Parasitology 63, 88-94. Fluorescence intensities were established by flow cytometry of different erythrocytic stages of Plasmadium berghei after staining of their DNA with Hoechst-33258 or Hoechst-33342. Parasites were obtained from highly synchronized infections or in vitro cultures. Most fluorescence measurements were performed using a low cost, clinical flow cytometer, equipped with a mercury arc lamp. Cells infected with $P$. berghei could be readily distinguished from uninfected cells on the basis of Hoechst-DNA fluorescence and single, double, and triple ring infected cells were separated clearly. The relative fluorescence intensities of different developmental stages (merozoites, ringforms, trophozoites, schizonts, and gametocytes) corresponded closely to the relative DNA contents of these stages as measured by microfluorometry. Flow cytometry appeared to be a sensitive and rapid method to measure DNA synthesis during asexual development; a $\mathrm{C}_{50}$ value of $5 \mu M$ of aphidicolin, a specific inhibitor of DNA synthesis, was established. Vital staining of parasites in culture was possible with both Hoechst dyes. After removal of Hoechst-33258, normal in vitro development of the stained parasites was observed. After Hoechst staining, the haploid ringforms of $P$. vivax showed slightly less fluorescence (15\%) than ringforms of $P$. berghei and $P$. falciparum. No differences in fluorescence intensity were observed, however, by direct microfluorometry after Feulgen-pararosaniline staining, indicating that all three species have the same DNA content. 1987 Academic Press, Inc.

InDEX DesCriptors AND ABbreviations: Plasmodium berghei; Plasmodium falciparum; Plasmodium vivax; Protozoa, parasitic; Malaria, rodent, human; Flow cytometry; Dyes, Hoechst-33258 and 33342; Deoxyribonucleic acid (DNA) synthesis; Aphidicolin; Base pairs (bp); Phosphate buffered saline (PBS); After infection (ai).
\end{abstract}

\section{INTRODUCTION}

Flow cytometry of malaria parasites has appeared to be a sensitive and rapid method to detect, count, and sort cells, infected with Plasmodium spp., after staining of their DNA with fluorescent dyes (Howard and Battye 1979; Brown et al. 1980; Saul et al. 1982; Myler et al. 1982; Whaun et al. 1983; Franklin et al. 1986). However, the use of this method to estab- lish DNA contents of different stages and the rate of DNA synthesis in parasite populations has been hampered by asynchronicity of infections, presence of multiple infected host cells, and lack of knowledge concerning the process of DNA synthesis in malaria parasites.

Recently, we were able to determine the exact time of DNA synthesis during asexual and sexual development of $P$. berghei, using direct microfluorometry of 
individual Feulgen-pararosaniline stained parasites (Janse et al. 1986). Ringforms and developing trophozoites during the first 15 hr of development are haploid. During schizogony, starting at $18 \mathrm{hr}$ after invasion of the host erythrocyte, the haploid amount of DNA is multipled 16-20 times within 4-6 hr. At the same time, limited DNA synthesis also occurs in maturing gametocytes up to $40-70 \%$ of the haploid amount.

The purpose of the present study was to compare flow cytometry and microfluorometry in assessing (1) DNA synthesis during intraerythrocytic development and (2) genome sizes of different malaria parasites.

The dyes Hoechst-33258 and 33342 (Loewe and Urbanietz 1974; Latt and Stetten 1976; Cesarone et al. 1979) were chosen for staining since these readily enter fixed and living cells in suspension (Arndt-Jovin and Jovin 1977) and have been reported not to be toxic for $P$. berghei (Howard and Battye 1979).

The present work shows that results obtained by flow cytometry of Hoechst stained cells fit very well with those obtained by microfluorometry in studying DNA synthesis during intraerythrocytic development but is less suitable for comparative genome size measurements.

\section{MATERIALS AND METHODS}

Synchronized infections of the ANKA-strain of Plasmodium berghei in Wistar rats and short term in vitro cultures of this parasite were obtained as described elsewhere (Mons et al. 1985; Janse et al. 1984, 1986), except that cultured mature schizonts were separated by Nycodenz gradient centrifugation (Nyegaard \& Co., Torshov, Norway). A detailed description of parasite morphology during synchronous development is given by Mons et al. (1985).

$P$. berghei merozoites, obtained from purified mature schizonts, were separated from (infected) erythrocytes essentially as described by Dennis et al. (1975).

$P$. berghei gametocytes, obtained from a synchronized infection at $28 \mathrm{hr}$ ai, were purified by Nycodenz gradient centrifugation: infected blood was layered on top of a $48 \%(\mathrm{v} / \mathrm{v})$ mixture of Nycodenz and culture medium (described by Janse et al. 1984) and centri- fuged at $350 \mathrm{~g}$ for $25 \mathrm{~min}$ at $4 \mathrm{C}$. Cells from the interfase, about $80 \%$ gametocytes, were collected.

$P$. vivax ringforms were obtained from a Dutch patient with a parasitemia of $0.3 \%, 7$ months after his return from Nepal. $\boldsymbol{P}$. falciparum ringforms (isolate NF54) were obtained from a synchronous culture established as described by Ponnudurai et al. (1986). Differential parasite counts in Giemsa stained bloodfilms were made in $5 \times 10^{3}$ erythrocytes.

For microfluorometry, thin bloodfilms were prepared, fixed, hydrolyzed, and stained with Feulgenpararosaniline $\left(\mathrm{SO}_{2}\right)$ (Chroma, Stuttgart, West Germany). In each experiment, 50 stained parasites were measured as described earlier (Cornelissen et al. 1984; Janse et al. 1986). For flow cytometry, cells were either fixed with $0.25 \%$ glutaraldehyde in PBS $\left(2 \times 10^{8}\right.$ cells $/ \mathrm{ml}$ ) for $10 \mathrm{~min}$ at $4 \mathrm{C}$, washed twice with PBS, stained with $2 \mu M$ Hoechst-33258 (Janssen Chimica, Beerse, Belgium) in PBS $\left(2 \times 10^{8}\right.$ cells $\left./ \mathrm{ml}\right)$ for $1 \mathrm{hr}$ at $37 \mathrm{C}$ in the dark, and analyzed within $1 \mathrm{hr}$, or living cells were stained with Hoechst-33258 or 33342 by adding them to in vitro cultures of $P$. berghei at $6 \mathrm{hr}$ ai at a final concentration of $10 \mu M$. After 1.5-2 hr of incubation at $37 \mathrm{C}$ in the dark, the medium was removed and the cells were resuspended in PBS at $4 \mathrm{C}$ and analyzed within $1 \mathrm{hr}$. To test their viability after Hoechst staining and incubation in PBS, about $10^{6}$ stained parasites were intraperitoneally injected into Swiss mice (20-25 g) or incubated in vitro under standard conditions for $20 \mathrm{hr}$ after two washings with prewarmed $(37 \mathrm{C}$ ) culture medium.

Hoechst stained cells were analyzed with a FACS Analyzer and a FACS IV (Becton, Dickinson, Mountain View, CA, U.S.A.). The FACS Analyzer was equipped with a mercury arc lamp (USHIO, Japan) and excitation was realized using a bandpass 360 and an SP 375 filter. An SP 375 was used as a dichroic mirror. The blue Hoechst fluorescence was selected with a bandpass 490 and two LP 400 filters. By gating on cell volume, erythrocytes and leukocytes were electronically selected for analysis, thus eliminating platelets, free parasites, and cellular debris. Fluorescence intensity measurements (linear or logarithmic gain setting) were collected for 50,000 cells per sample. Fluorescence histograms, divided into 256 channels, were processed and analyzed using the standard BD Consort 30 software. Cell sorting is not feasible with the FACS Analyzer. The FACS IV was operated with a high power argon ion laser with a laser emission of $20 \mathrm{~mW}$ in the ultraviolet light $(351 \mathrm{~nm} / 363$ $\mathrm{nm}$ ). Low angle light scatter and fluorescence signals were simultaneously detected for each cell. By electronic gating, erythrocytes were selected on the basis of their forward light scatter. Further details of operating conditions have been described by Howard and Battye (1979).

Fluorescence intensity measurements were collected for 50,000 cells per sample, and cells of interest 
were selected electronically and sorted with a speed of 1000 cells/sec.

Erythrocytic ringforms contain the haploid amount of DNA (Janse et al. 1986) and were, therefore, used as the reference value in flow cylometry and direct microfluorometry. Since fluorescence values of Hoechst stained erythrocytes, infected with a single ringform, showed a narrow symmetrical frequency distribution (see Results), the peak value, after subtraction of the mean "background" fluorescence of uninfected erythrocytes, is taken to represent the mean fluorescence value of ringforms $(1 \mathrm{C}=$ haploid value). Normally the background fluorescence was less than $10 \%$ the value of cells infected with ringforms.

\section{RESULTS}

Erythrocytes infected with one, two, and three Plasmodium berghei ringforms could be differentiated after Hoechst-33258 staining, with both the FACS Analyzer (Fig. 1A) and the FACS IV (Fig. 1B), and were clearly separated from uninfected cells on Hoechst-DNA fluorescence intensity. Double and triple infected cells showed fluorescence intensities of about two (mean of 2.05, 4 experiments) and three times (mean of $2.98,4$ experiments), respectively, the fluorescence value of single infected cells and microscopic exam-
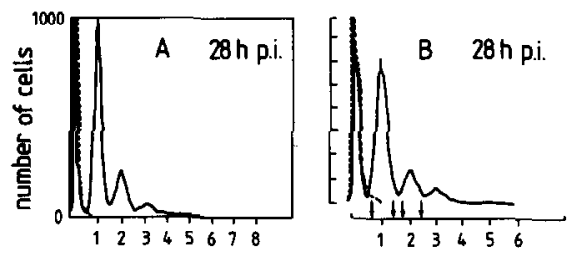

fluorescence intensity ( $c$-value)

FIG. 1. Frequency distributions of fluorescence values of infected erythrocytes present in a synchronous Plasmodium berghei infection at $28 \mathrm{hr}$ after infection (ai) (4 hr after reinvasion started), obtained with a FACS Analyzer (A) equipped with a mercury arc lamp and a FACS IV (B) equipped with a highpower argon ion laser, both after Hoechst-33258 staining. At $28 \mathrm{hr}$ ai, only ringforms (single, double, and triple infected erythrocytes) and gametocytes (less than $1 \%$ ) were present. The fluorescence channels selected for sorting (0.7-1.3C and 1.7-2.3C) are indicated. C-values were calculated as in Fig. 2. Dotted lines show the background fluorescence of uninfected cells at 0 hr ai. ination showed that mainly single (89\%) and double (82\%) infected cells were sorted from the first and second peak, respectively (Fig. 1B). Percentages of infected cells, as determined by flow cytometry, corresponded closely with percentages established in Giemsa stained bloodfilms (data not shown).

The fluorescence intensity of free merozoites (mean \pm SEM $(n): 0.96 \mathrm{C} \pm 0.0004$ $(40,000)$ ) was comparable to that of intraerythrocytic ringforms. Only a slight increase of fluorescence intensity $( \pm 10 \%)$ was observed during development of ringforms $(4 \mathrm{hr}$ ai) into large trophozoites $(16 \mathrm{hr}$ ai) (Fig. 2A,B). From the time the first schizonts appeared $(18 \mathrm{hr}$ ai), the percentage of cells with fluorescence values of

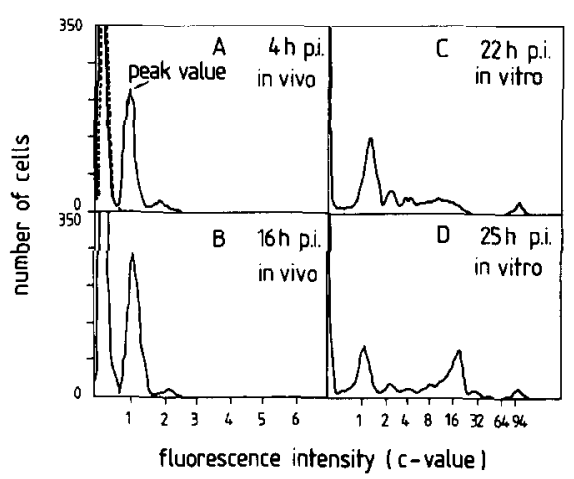

FIG. 2. Frequency distributions of fluorescence values of erythrocytes infected with Plasmodium berghei at 4, 16, 22, and $25 \mathrm{hr}$ ai, as measured by a FACS Analyzer after Hoechst-33258 staining. At $4 \mathrm{hr}$ ai, in vitro cultures were started with tail blood from a rat in which only ringforms (single and double infected erythrocytes) were present. During trophozoite development, from $4 \mathrm{hr}$ ai (A) until $16 \mathrm{hr}$ ai (B), parasites enlarge but do not synthesize DNA. At $25 \mathrm{hr}$ ai (D), most parasites were schizonts with 8-24 nuclei in the in vitro cultures and only $2 \%$ of the erythrocytes contained reinvaded ringforms. The "background" fluorescence of uninfected cells was established just before intravenous inoculation of purified schizonts (see dotted line in A). The haploid (1C) value is defined as the difference between the peak fluorescence value of singly infected erythrocytes (= first peak at $4 \mathrm{hr}$ ai) and the mean background fluorescence. Cells with values higher than $64 \mathrm{C}$ were leukocytes with a mean peak value of $115 \mathrm{C}$ ( 8 experiments $\mathrm{SD}: 7.4)$. $(\mathrm{A}, \mathrm{B})$ Linear gain setting; (C,D) logarithmic gain setting. 
over two times the haploid value increased (Fig. 2C) and in vitro, where schizonts hardly release their merozoites in the absence of shearing forces (Mons et al. 1985), the culture contained a high percentage of cells with fluorescence values of about $16 \mathrm{C}$ at $25 \mathrm{hr}$ ai (Fig. 2D). Purified mature microand macrogametocytes showed fluorescence values between 1 and $2 \mathrm{C}$ (mean \pm $\operatorname{SEM}(n): 1.4 \mathrm{C} \pm 0.002(36,000))$, confirming the results obtained with microfluorometry of Feulgen-pararosaniline stained gametocytes (Janse et al. 1986).

Using flow cytometry, the rate of DNA synthesis during schizogony was determined in the presence of different concentrations of aphidicolin, a specific inhibitor of DNA polymerase- $\alpha$ (Ikegami et al. 1978). DNA synthesis was inhibited progressively with increasing drug concentrations and $\mathrm{a}_{50}$ value of about $5 \mu M$ was established (Fig. 3). Living parasitesringforms, trophozoites, and schizontscould be stained with Hoechst-33258 as well as with Hoechst-33342. The fluorescence intensity of infected cells was dependent on the dye concentration in the culture medium and on staining time (data not shown) as was found earlier for the former dye (Howard and Battye 1979). Mice showed a normal infection pattern after inoculation of Hoechst-33258 and 33342 stained parasites and died within 7-14 days ai as did the control mice (6 animals/ group). In vitro, Hoechst-33258 stained ringforms/young trophozoites developed normally after removal of the dye. As in control cultures, $60-80 \%$ of the parasites were mature schizonts at $18 \mathrm{hr}$ after staining with 12-24 merozoites (3 experiments) capable of invasion. However, no development of ringforms was observed after Hoechst-33342 staining, even with a lower dye concentration $(5 \mu M)$, shorter staining time (1 hr), and more frequent replacement of the culture medium after staining. We have, at present, no satisfac-

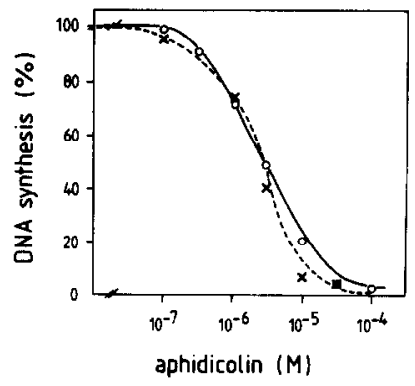

FIG. 3. Inhibition of DNA synthesis in asexual Plasmodium berghei parasites by aphidicolin, as measured by flow cytometry (FACS Analyzer) after Hoechst-33258 staining. Ringforms (4 hr after infection, ai) were incubated for $18 \mathrm{hr}$ under standard culture conditions with various aphidicolin concentrations. At 0 and $18 \mathrm{hr}$ of incubation, the fluorescence intensity of infected cells was determined. At $0 \mathrm{hr}$, infected cells had fluorescence values between 0.5 and $2.5 \mathrm{C}$ with a mean of $1.2 \mathrm{C}$ (single and double ring infected cells). At $18 \mathrm{hr}, 70 \%$ of parasites in the controls had fluorescence values higher than $2.5 \mathrm{C}$ with a mean of $10.1 \mathrm{C}$, while $30 \%$ had values between 0.5 and $2.5 \mathrm{C}$ (mean 1.3), thus had not yet started DN $\Lambda$ synthesis. At this time, about $26 \%$ of the parasites in the controls were still uninucleated. In all wells, parasitemia was constant during the culture period $(7.1-7.3 \%)$. The amount of DNA synthesized in each well is defined as the difference between the mean fluorescence value of infected cells at $18 \mathrm{hr}$ (which is corrected for the mean value of parasites that did not start DNA synthesis at $18 \mathrm{hr}$ in controls) and the mean fluorescence value at 0 hr. o Flow cytometry; $x$, direct microfluorometry (Janse et al. 1986), for comparison.

tory explanation why Hoechst-33342 stained parasites did not develop in culture while giving rise to normal infections in mice.

Erythrocytes infected with ringforms of $P$. vivax and $P$. falciparum could be distinguished from uninfected cells by flow cytometry after Hoechst-33258 staining, and fluorescence values showed a narrow symmetrical frequency distribution. $P$. falciparum had the same mean fluorescence intensity as $P$. berghei, whereas $P$. vivax showed a slightly lower value (Table I). The three different Plasmodium species showed no significant differences in fluorescence intensity after Feulgen-pararosaniline staining (Table I). 
TABLE 1

Fluorescence Intensity

\begin{tabular}{lcc}
\hline & $\begin{array}{c}\text { Feulgen-pararosaniline } \\
\text { mean } \pm \operatorname{SEM}(n)\end{array}$ & $\begin{array}{c}\text { Hoechst-33258 } \\
\text { mean } \pm \text { SEM }(n)\end{array}$ \\
\hline$P$. berghei & $100 \pm 0.7(50)$ & $100 \pm 0.15(2500)$ \\
$P$. falciparum & $101 \pm 0.7(50)$ & $102 \pm 0.09(7200)$ \\
$P$. vivax & $105 \pm 1.3(30)$ & $85 \pm 0.5(200)$ \\
\hline
\end{tabular}

Note. Mean fluorescence value of ringforms of Plasmodium berghei, $P$. falciparum, and $P$. vivax determined by flow cytometry (FACS Analyzer) after Hoechst-33258 staining and by direct microfluorometry after Feulgenpararosaniline staining. The mean fluorescence value of $P$. berghei ringforms is used as reference value and set at 100 .

\section{Discussion}

Recently, we determined the DNA content of asexual and sexual developmental stages of Plasmodium berghei by microfluorometry of individual Feulgen-pararosaniline stained parasites (Janse $e t$ al. 1986, and Introduction). This staining method has been used widely in quantitative measurements of DNA, based on the well-established assumption of a linear relationship between the amount of fluorescence and the original DNA content of stained nuclei (Duijndam and Van Duijn 1975; Prenna et al. 1974; Van ProoijenKnegt et al. 1980). Comparison of data obtained by microfluorometry with results presented in this paper shows that the fluorescence intensities of Hoechst stained $P$. berghei parasites correspond with the relative DNA contents of these parasites. The slight increase of fluorescence intensity observed during the first $16 \mathrm{hr}$ of trophozoite development, during which no DNA synthesis is expected, most probably is due to enlargement of the parasite cytoplasm, since we observed a faint fluorescence of the cytoplasm under the fluorescence microscope. From $16 \mathrm{hr}$ ai onward, the fluorescence intensity of asexual parasites increased to about 16 times the haploid value in mature schizonts.

Flow cytometry is an adequate method to study DNA synthesis inhibition by aphidicolin; a similar $\mathrm{C}_{50}$ value of about $5 \mu M$ was established as earlier found by microfluorometry (Janse et al. 1986).
In short, flow cytometry proved to be a sensitive and very rapid method to determine the onset and rate of DNA synthesis during schizogony. A disadvantage, however, is that parasites which have started DNA synthesis to two or three times the haploid amount cannot be distinguished from double and triple infected cells by the FACS, and it is evident that some details of the process of DNA synthesis during schizogony and gametocytogenesis, as published earlier (Janse et al. 1986), can only be determined by microfluorometry of individual cells. On the other hand, vital staining and separation of cells based on their different DNA content would make it feasible to select living cells with altered growth properties, e.g., aphidicolin resistant cells or temperature sensitive mutants (Arndt-Jovin and Jovin 1977).

By direct microfluorometry of Feulgenpararosaniline stained parasites, we found no significant differences in fluorescence intensities among the haploid stages of $P$. berghei, $P$. vivax, and $P$. falciparum, indicating that these specics have the same DNA content. By comparing Feulgen-pararosaniline stained sporozoites and metaphase human chromosome 21, this haploid genome size has been estimated in $P$. berghei as $2.5 \times 10^{7}$ bp (Cornelissen et al. 1984). After Hoechst staining, we observed no difference between the fluorescence intensities of $P$. falciparum and $P$. berghei; however, $P$. vivax showed a small but significantly lower value. This difference may 
be due to the preference of Hoechst dyes to bind to A-T rich regions of the DNA (Latt and Wohlleb 1975). $P$. falciparum and $P$. berghei have the same low G-C content $(18 \%)$ in contrast to the DNA of $P$. vivax which consists of a low and a high G-C content component (18 and 30\%, respectively) (McCutchan et al. 1984). As a result, we may expect a lower affinity of Hoechst dyes for Plasmodium vivax DNA.

\section{ACKNOWLEDGMENTS}

We thank Mr. P. F. J. van der Klooster for helpful suggestions and technical assistance and Miss E. van Dongen for typing the manuscript. The investigations were supported in part by the Foundation for Biological Research (BION), which is subsidized by the Netherlands Organization for the Advancement of Pure Research (ZWO).

\section{REFERENCES}

ARNDT-Jovin, D. J., AND Jovin, T. M. 1977. Analysis and sorting of living cells according to DNA content. Journal of Histochemistry and Cytochemistry 25, 585-589.

BRown, G. V., BatTYE, F. L., AND HowaRd, R. J. 1980. Separation of stages of Plasmodium falciparum infected cells by means of a fluorescence activated cell sorter. American Journal of Tropical Medicine and Hygiene 29, 1147-1149.

Cesarone, C. F., Bolognesi, C., and Santi, L. 1979. Improved microfluorometric DNA determination in biological material using 33258 Hoechst. Analytical Biochemistry 100, 188-197.

Cornelissen, A. W. C. A., Overdulve, J. P., AND VAN DER PLOEG, M. 1984. Determination of nuclear DNA of five Eucoccidian parasites, Isospora (Toxoplasma) gondii, Sarcocystis cruzi, Eimeria tenella, E. acervulina and Plasmodium berghei, with special reference to gametogenesis and meiosis in $I$. ( $T$.) gondii. Parasitology 88, 531-553.

Dennis, E. D., Mitchell, G. H., Butcher, G. A., AND COHEN, S. 1975. In vitro isolation of Plasmodium knowlesi merozoites using polycarbonate sieves. Parasitology 71, 475-481.

DuIJndam, W. A. L., AND Van Duisn, P. 1975. The influence of chromatin compactness on the stoichiometry of the Feulgen-Schiff procedure studied in model films. II Investigations on films containing condensed or swollen chicken erythrocyte nuclei. Journal of Histochemistry and Cytochemistry 23, 891-900.

Franklin, R. M., Brun, R., AND Grieder, A. 1986.
Microscopic and flow cytophotometric analysis of parasitaemia in cultures of Plasmodium falciparum vitally stained with Hoechst 33342 -application to studies of antimalarial agents. Zeitschrift für Parasitenkunde 72, 201-212.

Howard, R. J., AND BatTYE, F. L. 1979. Plasmodium berghei infected red cells sorted according to DNA content. Parasitology 78, 263-270.

Ikegami, S., Taguchi, T., Ohashi, M., Oguro, M., NAGONO, A., AND MANO, Y. 1978. Aphidicolin prevents mitotic cell division by interfering with the activity of DNA polymerase- $\alpha$. Nature (London) 275, 458-460.

JANSE, C. J., VAN DER KLOOSTER, P. F. J., VAN DER KaAy, H. J., Van Der Ploeg, M., AND OVerDULVE, J. P. 1986. DNA synthesis in Plasmodium berghei during asexual and sexual development. Molecular and Biochemical Parasitology 20, 173-182.

Janse, C. J., Mons, B., Croon, J. J. A. B., AND VAN DER KAAY, H. J. 1984. Long-term in vitro cultures of Plasmodium berghei and preliminary observations on gametocytogenesis. International Journal for Parasitology 14, 317-320.

LATT, S. A., AND STETTEN, G. 1976. Spectral studies on 33258 Hoechst and related bisbenzimidazole dyes useful for fluorescent detection of deoxyribonucleic acid synthesis. Journal of Histochemistry and Cytochemistry 24, 24-33.

Latt S. A., AND Wohlleb, J. C. 1975. Optical studies of the interaction of 33258 Hoechst with DNA, chromatin and metaphase chromosomes. Chromosoma 52, 297-316.

LOEWE, H., AND URBANIETZ, J. 1974. Basisch substituierte 2,6-Bis-benzimidazolderivate, eine neue chemotherapeutisch aktive körperklasse. Arzneimittelforschung 24, 1927-1933.

McCutchan, T. F., Dame, J. B., Miller, L. H., AND BARNWELL, J. 1984. Evolutionary relatedness of Plasmodium species as determined by the structure of DNA. Science 225, 808-811.

Mons, B., JaNSE, C. J., BoORSMa, E. G., AND VAN DER KAAY, H. J. 1985. Synchronized erythrocytic schizogony and gametocytogenesis of Plasmodium berghei in vivo and in vitro. Parasitology 91, 423-430.

Myler, P., Saul, A., Margan, T., and Kidson, C. 1982. An automated assay of merozoite invasion of erythrocytes using highly synchronized Plasmodium falciparum cultures. Australian Journal of Experimental Biology and Medical Science 60, 83-89. Ponnudurai, T., Lensen, A. H. W., Meis, J. F. G. M., AND Meuwissen, J. H. E. Th. 1986. Synchronization of Plasmodium falciparum gametocytes using an automated suspension culture system. Parasitology 93, 263-274.

Prenna, G., Leiva, S., and Mazzini, G. 1974. 
Quantitation of DNA by cytofluorometry of the conventional Feulgen reaction. Histochemical Journal 6, 467-489.

Saul, A., Myler, P., Mangan, T., And Kmson, C. 1982. Plasmodium falciparum: Automated assay of erythrocyte invasion using flow cytofluorometry. Experimental Parasitology 54, 64-71.

VAN ProOIJen-KNegt, A. C., Redi, C. A., ANd Van
DER PLOEG, M. 1980. Quantitative aspects of the cytochemical Feulgen-DNA procedure studied on model systems and cell nuclei. Histochemistry 69, 1-17.

Whaun, J. M., Rittershaus, C., and IP, S. H. C. 1983. Rapid identification and detection of parasitized human red cells by automated flow cytometry. Cytometry 4, 117-122. 